Maciej Ząbek

\title{
CONTINUITY AND CHANGE IN RURAL ARCHITECTURE IN SOUTHERN ANATOLIA
}

\author{
INTRODUCTION
}

Stanisław Leszczycki's study devotes a lot of space to the traditional architecture of Turkish homes. Half of 22 questions of the questionnaire constituting the basis for his research deal directly with architecture. Apart from detailed descriptions of architecture observed in the course of his research, Leszczycki outlines a general typology of architecture common for the whole of the Anatolia province. It could be expected that an analysis of such research material, compiled 60 years ago, would allow to define changes which occurred in this period. With regard to technologies and building materials, many innovations affecting architecture were made in the second half of the twentieth century. It could also be expected - as it was to some extent anticipated by Leszczycki - that the Turkish architecture would be affected by Atatürk's revolutionary reforms, which influenced the entire Turkish culture to such a considerable degree. Architecture is a sphere of human activity in which the growing ambitions and changing preferences are manifested in a relatively fast and distinct way; therefore, at least in theory, the opening up of Turkey to the influences originating in the west of Europe should also bring about changes in the styles of housing. In fact, however, comparison of contemporary Turkish homes with those described by Leszczycki demonstrates more continuation than revolutionary change. Additionally, Leszczycki's study lacks sufficient material for a closer examination of the question whether, and to what extent, the concept of the Turkish home has undergone change. Since Leszczycki perceived architecture solely as a component of landscape, he devoted a lot of space to description of the houses' shapes, and little to their functions, interior design, ecological considerations or the significance of individual elements. Lack of such information seriously impairs any attempt at a thorough examination of the process of any likely changes in that respect. Therefore this paper, apart from outlining the most conspicuous changes, primarily aims at emphasising the observable continuity of rural architecture in southern Anatolia, and supplementing Leszczycki's study with the missing information referred to above. 
It should also be observed that the perception of the Turkish architecture testifying to continuity rather than change might have been affected by the unintentional comparing of the Turkish architecture with the current state of architecture in the Polish countryside, where such continuity has been severed. Changes in the Turkish rural architecture are more subtle; even though those which took place over the past 10-15 years and are more easily observable are confined primarily to the applied technologies since the overall concept of the Turkish home has basically remained intact. A question might be asked why the Turks, so open to the western European cultural models since Atatürk's revolution, refrained from imitating these models in the sphere of architecture. It is true that no attempts were made in Turkey to administratively interfere with the rural housing (although this was the case in other areas of culture). Economic factors might be an important consideration, since building a house still remains one of the biggest investments, often a crowning achievement in life for people in many countries. Therefore, the state of housing to some extent epitomises the standard of living in a given country. Owing to the fact that Turkey was a poor country for many years following the revolution, obviously the cheapest and the most easily available solutions were opted for. Traditional housing was also the solution which had proved best with respect to its adaptation to the natural conditions, which determines the tradional type of culture everywhere in the world. Therefore, the houses were built in such a way as to provide protection for man and his animals against cold and dampness of winter and heat of summer. Environmental factors also account for the absence of burnt brick in traditional rural building industry. Since in areas where timber was difficult to obtain, using it for ceramics seemed an extravagance, therefore either stone or dried, unburnt brick typical of the entire Near East was used for building purposes. Only after rural brickworks fueled by mazout had become popular, burnt brick came to be a commonly used bulding material. Additionally, in newly-built houses such previously expensive materials as cement or sheet metal are contemporarily used. However, the concept of the Turkish home, which to some extent reflects the Turkish culture and lifestyle, has basically remained unchanged.

\section{TENT SETTLEMENTS ON THE ROUTE OF THE RESEARCH}

Tents, which once constituted a characteristic feature of the steppe landscape of Anatolia, connected with the nomadic style of life of numerous Turkish tribes, are currently very rarely encountered. We found a dozen or so small tent settlements of the Yürüks only in the Taurus mountains, between Korkuteli and Antalya. The time of the year may have been one of the reasons for the absence of nomads on these routes. In the summer the shepherds keep to the mountains and return to the valleys in winter, and 
therefore, in late September, when we were crossing these areas, they may not have been there yet. However, we failed to spot them in many other places in which Leszczycki, making his journey in summer, was able to see them. There were no tents either in the vicinity of lake Burdur or on Leszczycki's Eastern Route, in the valleys of Göksu and Ak Punar, where in Leszczycki's time there were many tent settlements. Besides, tents observed both by us and by Leszczycki did not belong to families entirely nomadic, but rather semi-nomadic, or determined to settle but still living in tents. The fact that tent settlements are nowadays extremely rarely found leads to the conclusion that the population of shepherds living in tents for the whole year or its part must have greatly diminished since then, and that the majority of those who settled down a long time ago built permanent houses. Referring to H. Wenzel, Leszczycki wrote than since the times of sultan Abdul Hamid II Yürüks had been encouraged to relinquish the nomadic way of life. Under Atatürk's regime, the authorities, as part of their efforts aimed at building a modern state, tried to settle Yürüks, Turkmens and Kurds. Thus, 60 years ago, some Yürüks had settled in the Taurus mountains and turned to agriculture as their basic means of subsistence; others remained semi-nomadic. Besides, neither Leszczycki encountered other groups of Turkish shepherds, such as nomadising Turkmens, who had started to settle in early 1900 s, nor did we.

Nomadism as a prevalent style of life in Anatolia, and tents as permanent dwellings, started to die out early in the beginning of the century. Leszczycki saw, to his surprise that "interestingly, despite all the changes the nomadic-shepherds' culture is still alive in this region". Not knowing the statistical data on the number of the nomadising shepherds then and now, on the basis of superfical observations only, we might reiterate Leszczycki's words, since the very fact that Yürüks living in tents throughout the year can still be met in such a modern and urbanised country as Turkey can be surprising. Despite the development of rural economy and the continual decrease area of grazing lands in Anatolia, nomads have been settling down at a slower pace than it was originally anticipated. It may be due to the fact that nomadic shepherding economy until this day remains one of the economically best ways of utilising mountain areas, which otherwise would lay waste. Additionally, profits from nomadic shepherding with relation to expenditure of labour must still be competitive for many people. Therefore, it is probably not so irrational and "unmodern" as it might seem, and has its niche in a free-market economy country. On the other hand, it also testifies to the great potential and attractiveness of the Yürük culture, which has so effectively resisted eternal influences. It is epitomised by tent settlements which can still be encountered on the routes, which are similar to those described by Wenzel and later, by Leszczycki.

The settlements we were able to observe, situated along the road from Korkuteli to Antalya were small, with two to four tents, facing different directions and usually inhabited by two-generation families. In one of the 
settlements we stayed for longer, there were three tents (çadir); one was inhabited by an old mother, the second by her son with wife and children, and the third one was used as a store. Residential tents stood about 10 metres from one another. Between them, there was a fire-place (hayma) with stakes around which served for hanging cloth or securing cardboard shielding from wind. In front of the fire-place, a vertical weaver's shop for weaving carpets was placed. A small flower garden, and a tent-store could be seen in front of the son's tent. The camp was surrounded with a fence of thorny xerophytes from three sides. On one side of the fence, there was a pile of chopped fuel timber, and on the other, an enclosure for sheep and goats. The yard in front of the tents was about 50 metres in length and 20 in width. The settlement was arranged in such a way that, if need arose, the sourrounding fence could be closed so as to provide enclosure for the animals.

The camp's tents were examples of the type classified by Leszczycki as great pole tents, rectangular, with the dimensions of about $4 \times 6$ metres, put up on 9 vertical stakes about two metres high (the centrally located stakes were higher, about 2.5 metres). On the top and on the sides, they were covered with black and brown cloth made of goatskin. Inside, along the stakes, there were household utensils covered with mats, rugs, blankets and propped pillows. Next to one of them, by the entrance, there was an elevated seat. The floor was covered with carpets or colourful rugs.

The type of the tent, its dimensions and the overall layout of the camp were identical with Leszczycki's description. The furnishings of the tents may have changed since we were able to observe gas cylinders, vacuum bottles, enamelled pots and plastic water containers, which certainly were not in use 60 years ago, although Leszczycki remarks only that "the tents were very modestly furnished". Along our route, we were also able to observe tents which Leszczycki described as small pole tents, pitched on five poles, with the dimensions of three by four metres and the height of about two metres, and having a similar construction to bigger tents. We failed to see, however, small tents pitched on a semicircular frame, which Leszczycki encountered near Ak Punar. According to Leszczycki, at his time the tents he described, which were connected with seminomadic economy, were being replaced by permanent shelters, which in turn were transformed into regularly visited summer camps called yayla. We did not observe any such camps during our journey, which means that most seminomads nowadays build permanent houses and are not economically forced to keep to shelters or tents.

\section{CUBE HOUSES OF THE EASTERN ROUTE}

According to Leszczycki, a traditional type of home on his Eastern Route was a Turkish type of house called by various authors a cube, oriental or Arabian house. Its characteristic feature are: a flat roof, walls made of 
stone or clay, lack of arcades and small windows. Houses of this kind have been built for many centuries, ever since production of brick from clay was known. They were built in Babylon and pre-dynastic Egypt. Well suited to the natural environment, nowadays they are normally built in woodless, steppe and desert areas. In the mountains, they are built of stone, and elsewhere - of clay. They provide good protection against excessive heat and temperature fluctuations, and owing to these features they were popularised by the Arabs throughout the Moslem world and in many peripheral areas. It should be stressed that the design of the cube house reveals not only the need for being sheltered against adverse climatic conditions, but also the wish to ensure privacy of the family life, which is characteristic for the peoples of the Near East, and has been reinforced by Islam. In Turkey, such houses can still be found in eastern Anatolia and on the southern coast. On our way from Antalya to Silifke we could see hip-roofed houses being gradually replaced by flat-roofed cube houses, while on the Eastern Route we were able to observe that they were the prevalent type of house. This, however, does not mean that no other type of housing can be encountered in this region, just as probably was the case in earlier times, since Leszczycki writes that "in all farming villages along the Eastern Route the Turkish cube house [only] prevailed". Unfortunately, Leszczycki did not analyse the local architecture more thoroughly as this would allow to define the actual tendencies more thoroughly. Certain changes, however, do seem to have taken place, and the classical cube house is being replaced to solutions typical of the whole architecture in Anatolia, that is bigger windows, doors and verandas. Additionally, single-storey houses described by Leszczycki as the most common ones, are replaced by two-storey houses with a high foundation, which can be encountered not only in the mountains. Newly-built houses do not follow the solutions used in the cube house; they are built in the contemporary Turkish way, that is, of burnt brick and concrete, with a hip roof covered with red tiles. Nonetheless, the cube house is the prevalent type in the region under research.

Stone (unworked limestone), bound with clay mixed with chaff or lime is the basic building material. Bigger, worked boulders are used as cornerstones. Timber, mainly poplar and pine, due to its high price is used only to make floor beams and pillars supporting ceilings of lower storeys. The houses are usually built by peasants themselves, who try not to hire masons. Summer is the typical building season, and once the materials are brought to the site, the building works rarely take longer than a month. The foundations are laid at the depth of one to two meters. High foundations are used as underground cowhouses, barns and stores, hence the building is in fact two-storey.

The walls are about half a metre thick and 2.5 metre high. They are occasionally plastered with clay or painted. The ceilings in the rooms are made of floor boards or beams, and support a flat roof.

The roofs not only provided protection against rain, but also insulation 
against the heat lasting for many months. They have been invariably flat, slightly slanting towards the facade, which speeded up the flow of rainwater. On a scaffolding of poplar beams, poles and a layer of branch wood reaching beyond the houses' walls are placed. In this way, the roof is slightly protruding, thus creating a cornice protecting the walls against rain. Bundles of bulrush are placed on the branch wood, subsequently covered with a thick layer of clay, wet-rolled with stone cylinders, which are sometimes fragments of columns from ancient buildings. Following rain, parts of roofs tend to be washed away, therefore roofs require systematic replenishing with clay mixed with chaff, and rolling. For this reason, stone cylinders are an inherent component of roofs. Such roofs very efficiently protect against frost and heat. Although houses made of brick and concrete, with sheet-metal roofs, are more solid, their dwellers are pestered with cold, dampness and suffocating heat all year long, which forces them to install costly heaters or air-conditioning systems, which in turn boosts the overall costs of this more expensive type of house. Unsurprisingly, therefore, flat- roofed cube houses effectively compete with them even today, although sheet metal as roofing has been known for a long time, which was also confirmed by Leszczycki. In addition, roofs of cube houses are used for drying vegetables, grain, hay, and for sleeping in summer. Leszczycki often stayed in such houses during his journey.

Doorways and windows are normally rectangular, lined with brick and clay and reinforced with door frames. Houses with small single-paned windows described by Leszczycki are no longer encountered.

At present, housing in this region does not demonstrate such uniformity of building materials and construction as was described by Leszczycki; apart from the typical stone, burnt clay is used as a building material. Furthermore, houses are now bigger than before; one- or two-room houses have been completely replaced by four-room ones, which Leszczycki was also able to observe, but he qualified to such houses as more modern.

\section{ARCADE HOUSES OF THE WESTERN ROUTE}

The arcade house was characteristic for Leszczycki's Western Route. Such houses were built of field stone (predominantly limestone), bound with clay, or of dried brick. Sometimes the lower part was made of stone, and the upper of dried brick. Normally such houses require a considerable amount of timber to build, mainly poplar beams. They are set in the walls between the foundation, ground floor and upper floor, often in the corners; sometimes they constitute the entire frame - the structure for the upper floor. The roof and arcades, the characteristic feature of the region's architecture, are supported by wooden studs and porters. Occasionally, timber members are interlocked, and empty spaces between the frames are nogged with dried brick. Sometimes, the structure frame is planked. To the boards, slats 
are nailed as a preparation for plastering with clay. Parts of walls are built of wooden beams. Walls are usually plastered with clay and often whitewashed or painted yellow.

In comparison with cube houses, arcade houses are more complicated with regard to building technology; also, their construction requires more wood. Leszczycki quotes after Wenzel that such a house can last approximately 100 years; the actual age of the oldest houses encountered on the route was about 100 years. However, the newest houses built in this style were at least 20-30 years old. This proves that such a housing style, despite still being common, is increasingly becoming a thing of the past. More recent houses are built differently. Concrete, steel and burnt brick are entirely replacing stone, wood and clay. Additionally, flat roofs, similarly to those in cube houses common in arcade houses in Leszczycki's time, have completely disappeared from the local landscape. Hip houses, with elongated roof ridges and covered with red tiles, which were rarely seen at his time and were regarded by Leszczycki as examples of influence of the neighbouring cities, are nowadays common. Such houses are found not only in arcade houses, but also in quite newly-built houses. Another element missing in Leszczycki's time are satellite dishes and sun batteries for heating water in special tanks, now constituting an inherent part of landscape. Besides, small gable-wall windows can no longer be observed; they have been replaced by bigger windows (at least $60 \times 80 \mathrm{~cm}$ ) in front and side walls. In houses most recently built, arcades and verandas give way to the apparently trendier balconies ad terraces.

\section{ORIGIN OF THE OVERALL CONCEPT AND BASIC PRINCIPLES OF THE TURKISH HOME}

The overall concept of the traditional house in Turkey was influenced by historical and ecological considerations, cultural traditions of the tribes which arrived in Anatolia from Central Asia, and religious ideas and beliefs it adopted.

Basic architectural assumptions of buildings and building technologies are to some extent a continuation of the same solutions which have been widespread among the ancient civilisations developing in the eastern part of the Mediterranean Sea since Neolithic times. Local geological conditions and the degree of woodiness determined the use of specific building materials. They contributed to using timber for building purposes on a large scale in the north of Anatolia; mud and stone in its central part, and timber, clay and stone in the south. Naturally, the materials which were used determined architectural solutions. Climatic conditions in turn enhanced their differentiation. This influence can be seen in the functions of individual rooms in various seasons. Generally, rooms are divided into summer and winter ones. The latter are warmer, better insulated (thicker walls), with 
smaller windows (with shutters) and doors built in the wall which is sheltered from cold winds. Additionally, they are heated with a fireplace either constituting an inherent part of the house's structure, or by metal stoves. The rooms' dimensions are also smaller, to make heating easier. Once the weather changes to cold, the dwellers move to the better insulated and heated room. On the other hand, summer rooms are built of light materials, have big windows and overlock the direction from which cool breezes blow in the summer.

Since the topographic features did not influence the concept of the traditional house, despite their ostensible variety, residential houses across Anatolia are characterised by the same assumptions concerning lifestyle and furnishing the house interior. Interior design was basically influenced by shepherds' tradition of living in tents. Usually the basic dwelling unit of the Turkish nomads who arrived from the steppes of Central Asia consisted of several round, dome- shaped tents pitched on light frames, similar to yurts still used in Central Asia. The furnishing of such a tent depended on, and was adopted to the living conditions. In the centre, there was a fire-place (ateş yeri), opposite the entrance - room for saddle-bags, packs and saddles $(y u k)$, to the right of the entrance one or two horse- skin sacks (saka) for fermented mare's milk were placed, separated with a screen of woollen mats (cig); next to it, there was a bed which also served as a seat for the tent's owner. By the bed, clothes, tools and weapons hang on the poles inserted into the ground. To the left of the entrance was the room for saddle frames and horse gear. Additionally, the tent's furnishings included also wooden bowls, skin bottles and bags, and a weaving shop for weaving clothes ad carpets.

In Anatolia, the Turks started to farm land and change the nomadic to the sedentary way of life, even though some tribes such as Turkmens or Yürüks maintained the nomadic way of life till modern times. Those who settled down, however, began to dwell in permanent houses, and abandoned their movable dwellings. Yet, regardless of the materials used and the external shape, the houses were furnished like tents. Since a house offers more space, it brings together more people under one roof than a single tent. For this reason, the characteristic feature of such houses was the open, common room called sofa or hayat, which had a similar function to the space between the tents. Thus, sofa became the cardinal element of the Turkish house and influenced its shape. Being common space between the rooms, it provides access to them and serves as a meeting and resting place. Depending on the needs of the family and wealth of the owner, individual rooms can be added to it. Each room has a door opening off to the corridor or sofa and, just as a shepherd's tent, it is used for eating, resting, working and sleeping. In traditional rural homes, separate dining-rooms or bedrooms are not encountered. Since individual rooms fulfil the basic function of the tent, their dimensions are similar. Only the circular shape of the old tents has been replaced by rectangular one, which is due to the way the 
house is structured. Room for storing packs, saddle-bags and bags has now been converted into wardrobes, enclosing the usable area, although in some houses clothes and packs hang in visible places. The movable elements of the interior such as floor coverings (similar to the ones in tents - carpets, kilims, blankets, thick felt), beds, and various chests, suitcases, packs, parcels etc. have been preserved.

Religion (Islam) was also a factor influencing the basic principles governing the furnishing of a Turkish house. Accordingly, the living environment had to be enclosed and intimate, and the house divided into the men's part (bas oda or selamlik) and the women's part (harem). Men in Turkey, regardless whether they work or not, spend most of the day out, and normally return home in the evening. Therefore bas oda is more like a guest room than a man's personal room, and is an equivalent of sofa. On the other hand, women work, rest and meet other women at home, therefore women's rooms, although more modestly furnished than bas oda, were provided with comfortable facilities for sitting, sleeping and eating.

Houses are normally two-storey, and the ground floor has non-residential functions. Interestingly, the owner's wealth and the period of completing the house's construction hardly affect its shape or furnishings. Technologies, dimensions, decorations and construction details change, but the basic features characteristic for the Turkish house remain the same throughout the region.

\section{TYPICAL INTERIOR ELEMENTS OF THE TURKISH HOUSE}

WINDOWS

According to Leszczycki, windows in both types of houses were small, with iron bars and shutters, seemingly playing an insignificant role in the house's structure. In fact, windows constitute an important element of the rooms' interior and the external design. Owing to the cultural traditions emphasising the intimate character of home, the windows in lower storeys are reduced to a minimum, have bars and shutters thus ensuring safety and privacy for the upper floor, which has many windows. Windows in the upper-floor rooms are usually close to one another in order to provide maximum light, ventilation and better view. It might be said that the windows are an external manifestation of the outlook on life of the dwellers. Although Leszczycki disregards this important element in his description, it can be concluded on the basis of some photographs from his work and the preserved buildings that such windows were also observable earlier, even though contemporarily they are definitely bigger and appear on lower storeys. It may be a proof of an increased openness of family life, resulting from the overall cultural changes. 
THE FLOOR

For nomadic shepherds, "the sky was above and the earth beneath", and this saying reflects the perception of space in permanent houses, where the floor constitutes "the earth", and the ceiling 'the sky". Floors are covered with various carpets, kilims, mats or thick felt so as not to "trample the earth". One enters the room barefoot, leaving the shoes outside. The floor is also the area where one can sit with crossed legs or on one's knees, eat food and say ritual prayers. In this way, traditions express close contact of man with nature, and at the same time the carpets covering the floor symbolically depict the barrier between man and the earth. This role of the floor typical of Turkish homes, relating to the pre-nomadic period, has been preserved until this day not only in villages, but also in the most modern houses.

\section{THE CEILING}

The ceiling, as the symbolic sky, constitutes one of the major elements of the Turkish home. In old buildings, the ceiling is the most ornamental surface in the room, adorned with geometrical patterns. This, however, depends on the status of the owner and the function of the room. Normally, decorated ceiling could be found only in the host's room. Such rooms are usually square. However, even if they are rectangular, the ceiling's surface is so arranged as to give a semblance of the square, which is always easy to divide and decorate. Regardless of regional differences, decoration of the ceiling is governed by several principles. In ordinary rooms, beams can be painted, waxed or left in their natural state. In more prominent rooms, small-sized slats are nailed onto the beams, which are decorated by sculpting, inlaying or tessellating. The ceiling can also be covered with small wooden tiles of varying patterns, or plaster, paper or cloth. In recently built houses, however, decorated ceilings are no longer encountered.

\section{SEATS}

Apart from the floor, a special elevated wooden platform surrounding the room from three sides, called sedir, is used for sitting. Most often, it is connected with the floor and constitutes a permanent element of the house's structure. Covered with soft cloth and blankets, it makes a comfortable seat. Depending on the region, sedir can slightly differ. However, regardless of the house's building material, it remains a permanent element of the Turkish home both in the country and in towns. Currently, only in most recently built houses the wooden platform is replaced by settees, folding couches, or even chairs arranged in a row. 
One of the main features of the Turkish home are various kinds of cupboards and closets for petty objects. Each of them has its own name depending on the function, for instance: yüklük (bedsheets), kavukluk (turban), testilik (jugs), peşkirlik (table-cloths, napkins, diapers), lambalik (lamps), cezvelik (coffee pots), fincanclik (cups), çiçelik (flowers), feslik (fez), degneklik (walking sticks) etc. They have the form of wooden panels, which may occasionally cover the whole wall. Since such closets are expensive, in many less prominent rooms various items, packed in bags and packs, hang on the walls. Contemporarily, furniture not found earlier in rural homes, such as tables, chairs, beds, cabinets and cupboards for glasses, cups or crystal is quite common

\section{HEATING}

According to Leszczycki's description, the houses he encountered on both routes were provided with open fire places, above which chimneys made of limestone bound with clay and covered on top with a flat stone protecting the fire against rain were erected. Such simple fireplaces are used until this day. In less prominent rooms or older houses, the fire places are not even covered with a hood; hoods (occasionally decorated) can be found only in more prominent rooms. In summer rooms heating is not used. Undoubtedly, the heating system in old and new rural houses alike is not well developed. Houses are built in such a way as if they were not designed for heating, therefore the heat of the fireplace is not always sufficient. Nowadays this lack of warmth is compensated by adding coke stoves. However, this type of heating does not suit well the rooms' structure.

\section{CONCLUSIONS}

By way of conclusion, it should be said that a number of changes have taken place in architecture since Leszczycki's research. Although easily observable, these changes have not affected the basic tenets of the Turkish culture. They are primarily due to improved economic conditions in Turkish rural areas, although this process has certainly been slow, and more significant changes occurred in recent years. Most of the small and technologically simpler houses of both the cube and the arcade type, described by Leszczycki as rather common in the region, can no longer be seen. Only those buildings which Leszczycki referred to as more modern or modelled after urban housing have remained. Over the past fifty years, they have dominated the entire regional architecture. Although currently cube houses and arcade houses are still characteristic features of the region's landscape, abandoning the traditional building styles for the sake of standard single- 
family housing using concrete, hollow brick, burnt brick and red tiles can be seen across the country.

At the same time, a characteristic continuity with regard to the general concept and the interior design can be observed. It is closely connected with the historical, cultural and religious traditions of the region, and more loosely - with environmental considerations. This continuity does not depend on the regional conditions regarding construction trade or changes in building materials or technologies, and equally applies to cube houses, arcade houses and the contemporary single-family housing. Similarly, economic factors insignificantly affect the basic principles of the Turkish home.

As regards the external design, changes are manifested in the harmonious combination of religious principles stressing the significance of the privacy of the living environment with the openness of nomadic settlements. This is expressed in the tendencies concerning the compactness of the house's structure, reducing the number of lower-storey windows on the one hand, and on the other - in enlarging verandas, balconies and windows on upper storeys, and the existence of common space between the rooms.

With respect to the interior design, continuity is demonstrated in adapting the living space to the specific style of life dating back to pre-settlement age. Functions of such elements of the interior as the floor, ceiling, elevated seats are not subject to change. Moreover, the division into summer and winter rooms is maintained as well as disregarding the importance of heating, which is typical of countries enjoying a warm climate. 